\title{
Frequency dependent permittivity of soil and bentonite: for lightning protection and high frequency earthing systems
}

\begin{abstract}
This paper presents the frequency dependent permittivity of a selected type of soil, bentonite and four of their mixes by weight. The permittivity at a low frequencies, vary significantly with moisture content in the cases of both sand and bentonite. For dry sand, bentonite and all bentonite mixes, the permittivity shows a rapid drop with the increment of frequency from near $0 \mathrm{~Hz}$ to $0.6 \mathrm{kHz}$, followed by a moderate decrement up to about $10-20 \mathrm{kHz}$. All parameters have rather insignificant variation after about $50 \mathrm{kHz}$ and level of around $1 \mathrm{MHz}$. These outcomes provide some key information to analyze the behavior of bentonite based backfill materials that are widely used in electrical earthing networks, especially in the case of high frequency earthing and lightning protection systems.
\end{abstract}

Keyword: Lightning; Earthing; High frequency; Bentonite; Permittivity; Electrical parameters 